Encounters on Education

Volume 2, Fall 2001 pp. 1-5

\title{
Introduction
}

\section{Educational reforms: International perspectives \& local idiosyncracies}

\section{Rosa Bruno-Jofré \& Gonzalo Jover}

Queens University \& Universidad Complutense de Madrid

7 His issue of Encounters/Encuentros/Rencontres is devoted to educational reform internationalization and its coexistence with regionalization, hybridity and the almost obvious dominance of Anglo-American influenced educational research (Schriewer, 2000, p. 316). Educational reform is the subject of intense political debate in many parts of the world. As Popkewitz (2000) put it, in most countries educational reform is considered a "strategic site for intervention": a means to enhance economic viability and to link the macro components of regulation to the micro patterns of socialization. This issue also features a paper dealing with representation of women in research in relation to the study of immigration, culture and ethnicity.

This collection is divided into four parts:

I EDUCATIONAL REFORM IN SPAIN;

II THEMES IN CANADIAN REFORM;

III THE FUTURE OF EDUCATION IN LATIN AMERICA: A CRITICAL VIEW; and

IV METHOdOLOGICAL ISSUES.

Although Canadian and American authors have called for the analysis of commonalities and differences in industrialised countries (Levin, 2000), the analysis of educational reform in Spain has been mostly neglected by North American authors(Garcia Garrido, 1993, pp.19-22). This is certainly an important limitation in current literature, in particular given the historical, cultural, and linguistic relations between Spain and Latin America. In turn, Spanish readers of this volume will find original research on various aspects of the educational reform in Canada (Garcia Garrido, 1993, pp. 19-22).

The Spanish papers address transformations that have taken place in the Spanish educational system over the past twenty years. These changes were encouraged by the 
political change crystalised in the Constitution of 1978, the modernization of the country, changes in Spain's social fabric, and its integration with major European institutions. At the same time, these papers examine local responses to change and adaptations to local variants of international trends that originate in the political, cultural, or economic sphere and directly affect educational systems. The reader will note that the authors pay attention to (a) the re-definition of political spaces in relation to tensions generated by the simultaneous movement to integration in supra-national units and to dominance of regional spaces; (b) the increasingly multicultural character of Spanish society; (c) the hegemony of a neo-liberal economy.

\section{Part I}

Part I, EDUCATIONAL REFORM IN SPAIN includes three papers. The first one, entitled "The reform of the Spanish education system: An evaluation and prospective," was written by Gonzalo Vázquez. He places the analysis of the Spanish educational system and explores issues and challenges in relation to international and European trends. His analysis explains how those trends force us to rethink old tensions in a new light. Vásquez refers to: (a) issues of equity within diversity; (b) tensions between the pursuit of excellence and the expansion of educational opportunities; and (c)challenges deriving from a decentralised system. The educational system is pushed to adapt itself to a complex dynamic generated by social changes. Thus, there are increasing demands while education remains devalued, placed outside the area of social co-reponsibility, and often lacking the injection of needed resources and a commitment to the adequate preparation of educators. In light of the work of international organizations, Vásquez concludes by discussing challenges involved in the process of integrating personal education and professional training, and recreating the system to allow for the integration of the idea of education as a life-long and life-wide process.

The perception that educational reforms often fail to change school practices in a significant way is not unique to Spanish researchers. Antonio Viñao examines this perception from the perspective of new approaches to the history of education, in the paper entitled "Do education reforms fail? A historian's response." He uses, in a critical manner, the concept of"

"school culture" (European terminology) or "grammar of schooling" (American terminology). Each school can be analysed as a microcosm in which there are various interwoven and conflicting cultural frameworks: the culture of teachers, of parents, of students, etc. The partnership of academic specialists and civil servants (políticosadministradores) tends to alienate teachers, who usually react against any attempt at change from above. This perpetuates the perception that things continue as usual. This historical analysis provides the necessary perspective to complement an analysis based on the school culture. The historian exposes internal contradictions in the processes of reform, changes in the social and political context, the interplay of interests, power changes, etc., that take place over time.

Part I closes with "The European focus of the curriculum in the educational reforms in Spain at the end of the twentieth century," by Leoncio Vega. It situates recent 
changes in the Spanish educational system in relation to the educational policies of the European Union. In fact, the Law on General Organization of the Education System (I990), which introduced structural changes at the primary and secondary level in the Spanish system, was a response to needs emerging from Spain's integration in the Union. The situation has acquired, from a normative perspective, a new dimension since 1992, when education was included within the sphere of competence of the Union. Vega examines the repercussions of the European formation on Spanish curricular matters by comparing initiatives and policies within the European context such as the Action Program, the Green Paper and the Socrates program with policies and initiatives coming from Spain.

\section{Part II}

Unlike the Spanish papers, which provide comprehensive views of reform, the Canadian papers have a thematic quality. Part II, entitled THEMEs In CANADian REFORM, contains three papers. It opens with "Devolution and Control in Alberta," written by Alison Taylor. Education in Canada is under provincial jurisdiction. However, educational reforms that took place in several provinces of Canada such as Manitoba, Alberta, and Ontario in the I990s had similar features that they also shared with other English speaking countries, in particular Australia, the United Kingdom and the United States. Common themes of reform have been the movement toward outcome-based programs, design and implementation of standardised testing, common curriculum standards, introduction of a new report card, teacher recertification (in the case of Ontario), increasing involvement of business in determining educational aims, accountability and overall extensive cutbacks that have affected counselling, special education and teacher librarian staff. Feelings of deprofessionalization became pervasive among teachers.

Taylor, who has written extensively on educational changes in Alberta, considers the dominant trends in various countries but roots her analysis in the Alberta context, paying great attention to the policy process and how it works. The paper focuses on two elements of the reform package introduced in 1994 that reflect the shift toward devolution and centralised control in the Alberta system: (a) school-based management and (b) changes to the collection and allocation of education funding. The conclusions are remarkable. Cuts to education funding were a key driver of the restructuring in education, which quickly initiated a domino effect in the powerful Alberta Department of Education. Interestingly, Taylor's findings indicate that the Department focused on the early phases of the policy associated with school based management and paid less attention to implementation and evaluation of outcomes. Issues regarding equity across districts received little accommodation by the government and little attention from the public. For the public, devolution meant downloading the stress of budget cuts. In Alberta, as in other places, there was a shift in the provision of public services, an accentuation of technocratic forms of governance, and less attention paid to equity issues. It is a reformulation of schooling as a public institution. 
The paper by Samuel Mitchell, "Partnerships and charter schools: Contrasts in Canadian reform" argues for the need to relate charter schools to partnerships. It is an argument to support the development of charter schools in Canada, an issue that has been discussed by teachers and scholars in relation to the erosion public education. Mitchell dismisses that critical approach. His notion of partnership is broad, bottomup, and advocates the inclusion of disparate partners such as community services, business, parents, teachers, professionals, etc. When opposing charter schools, teachers, in his view, act as a sectarian group. He believes that teachers underestimate the contribution of partnership, a basis from which, in his view, equality and participation in education could be achieved. This is a challenging and controversial article advocating an optimistic and practical view of partnership.

Part II closes with "The market model of education and the threat to Canadian university" by Howard Woodhouse. In contrast to the previous chapter, Woodhouse pursues a critical analysis of the educational values of many corporate organizations. He uses John McMurtry's analysis of the market model of education which shows that the market threatens universities' autonomy as well as their ability to advance knowledge for the public good. This critical framework allows Woodhouse to analyse statements advocating the market model by such sources as the Corporate Higher Education Forum, the Expert Panel on the Commercialization of University Research, The Corporate Council on Education of the Conference Board of Canada, government officials and university administrators. Woodhouse offers a sophisticated explanation of the implications of closely linking universities to economic growth and the imperative of the corporate market. The point is that the goals of the market are quite different from the goals of education and that market goals actually undermine the values of education. As the author writes, "one aims at material possession of uniform artifacts, while the other strives for knowledge that enhances the distinctive mental capacities of those who seek it." The reader will find a well argued case for the university as an institution serving the public good.

\section{Part III}

Part III, THE FUTURE OF EDUCATION IN LATIN AMERICA: A CRITICAL VIEW, comprises an article by Evelia Derrico entitled "Calidad y equidad en el futuro de la educación: El problema de la igualdad de oportunidades sigue siendo un problema” (Quality and equity in the future of education: equal opportunity continues to be a problem). This Argentinian educator gives a Latin American perspective to the analysis of educational changes in light of information technology and globalization. She calls attention to the inequity experienced by those who do not have access to education and also by those who, having access, are still denied quality education. She refers to a new form of exclusion accentuated by the uneven distribution of resources such as appropriate infrastructure in Latin American countries, and costs related to the production and use of online programs, among others. Derrico develops a thorough critique and offers solutions at the curricular and administrative levels. She sees education for work as leading toward full formative human development, and questions the persistent traditional 
pedagogical approach to technological education and poor integration of communication techniques and multimedia. Derrico's proposals are based on the principle of educational complementarity which allows formal and non formal systems as well as educational contextual situations to support each other, leading toward self-reliance.

\section{Part IV}

This issue closes with a paper on methodological issues: Yvonne M. Hébert's "Représentation de la femme en tant qu'objet et agent de recherche" (Representation of women as object and agent of research), a much-needed methodological analysis of women's representation in research with reference to the study of immigration in Canada, and taking into consideration studies of ethnicity and culture. It explores challenging questions: What were the methodological changes through the years; in particular from the I950s? Why? Which parallels can be established, on one side between the methodological aspects concerning feminist pedagogies, practices and processes which are integral part of the comparative analysis of the sexes, and on the other side, the methodological changes that took place in the research on ethnic belonging and cultural studies? How should we integrate these methodologies into research on immigration?

This issue of Encounters/Encuentros/Rencontres continues the encounter of points of interest, standpoints, and academic traditions that we started a year ago with an issue devoted to citizenship and education in Canada and Spain. We would like to thank our readers for their positive reception of this international project.

\section{References}

García Garrido, J.L. (1993). Sistemas educativos de hoy. Madrid: Dykinson.

Levin, B. (200I). Reforming education: From origins to outcomes. Dondon: Routledge/Falmer. Popkwitz, T. (2000). Globalizaton/regionalization, knowledge, and the educational practices: Some notes on comparative strategies for educational research. In T. Popkewitz (Ed.), Educational knowledge: Changing relationships between the state, civil society, and the educational community (pp. 3-30). Albany, N Y: State University of New York Press.

Schriewer.J. (2000). World system and interrelationship networks: The internationalization of education and the role of comparative inquiry. In T. Popkewitz (Ed.), Educational knowledge: Changing relationships between the state, civil society, and the educational community (pp. 395-345). Albany, N Y: State University of New York Press. 
